\title{
Article
}

\section{Elite football of 2030 will not be the same as that of 2020: What has evolved and what needs to evolve?}

Harper, Damian James, Sandford, Gareth N., Clubb, Jo, Young, Megan, Taberner, Matt, Rhodes, David, Carling, Chris and Kiely, John

Available at http://clok.uclan.ac.uk/36592/

Harper, Damian James, Sandford, Gareth N., Clubb, Jo, Young, Megan, Taberner, Matt, Rhodes, David ORCID: 0000-0002-4224-1959, Carling, Chris and Kiely, John ORCID: 0000-0001-9817-0224 (2021) Elite football of 2030 will not be the same as that of 2020: What has evolved and what needs to evolve? Scandinavian Journal of Medicine \& Science in Sports, 31 (2). pp. 493494. ISSN 0905-7188

It is advisable to refer to the publisher's version if you intend to cite from the work. http://dx.doi.org/10.1111/sms.13876

For more information about UCLan's research in this area go to http://www.uclan.ac.uk/researchgroups/ and search for <name of research Group>.

For information about Research generally at UCLan please go to http://www.uclan.ac.uk/research/

All outputs in CLoK are protected by Intellectual Property Rights law, including Copyright law. Copyright, IPR and Moral Rights for the works on this site are retained by the individual authors and/or other copyright owners. Terms and conditions for use of this material are defined in the policies page. 


\section{SCANDINAVIAN JOURNAL OF MEDICINE \& SCIENCE IN SPORTS}

\section{Elite Football of 2030 will not be the same as that of 2020: What has evolved and what needs to evolve?}

\begin{tabular}{|r|l|}
\hline Journal: & Scandinavian Journal of Medicine and Science in Sports \\
\hline Manuscript ID & SJMSS-L-1061-20.R2 \\
\hline Manuscript Type: & Letter to Editor \\
\hline Author: & n/a \\
\hline Complete List of Authors: & $\begin{array}{l}\text { Harper, Damian; University of Central Lancashire, School of Sport and } \\
\text { Health Sciences } \\
\text { Sandford, Gareth; University of British Columbia, School of Kinesiology; } \\
\text { Canadian Sport Institute Pacific } \\
\text { Clubb, Jo; Buffalo Bills } \\
\text { Young, Megan; Chicago Red Stars } \\
\text { Taberner, Matt; Liverpool John Moores University } \\
\text { Rhodes, David; University of Central Lancashire, Institute of Coaching } \\
\text { and Performance } \\
\text { Carling, Christopher; French Football Federation, Centre for Elite } \\
\text { Performance } \\
\text { Kiely, John; University of Central Lancashire, School of Sport and Health } \\
\text { Sciences }\end{array}$ \\
\hline Keywords: & \\
\hline &
\end{tabular}

\section{SCHOLARONE ${ }^{m}$ \\ Manuscripts}




\section{LETTER TO THE EDITOR}

Elite football of 2030 will not be the same as that of 2020: What has evolved and what needs to evolve?

Damian J. Harper ${ }^{1}$, Gareth N. Sandford ${ }^{2,3}$, Jo Clubb ${ }^{4}$, Megan Young ${ }^{5}$, Matt Taberner ${ }^{6}$, Dave Rhodes $^{1}$, Chris Carling ${ }^{7}$ and John Kiely ${ }^{1}$.

${ }^{1}$ School of Sport and Health Sciences, University of Central Lancashire, Preston, UK

${ }^{2}$ School of Kinesiology, University of British Columbia, Vancouver, BC, Canada

${ }^{3}$ Canadian Sport Institute-Pacific, Victoria, BC, Canada

${ }^{4}$ Buffalo Bills, Buffalo, USA

${ }^{5}$ Chicago Red Stars, Chicago, USA

${ }^{6}$ School of Sport and Exercise Sciences, Liverpool John Moores University, Liverpool, UK

${ }^{7}$ Centre for Elite Performance, French Football Federation, Paris, France

Correspondence:

Damian J. Harper, School of Sport and Health Sciences, University of Central Lancashire, Preston, PR1 2HE, UK. Email: dharper5@uclan.ac.uk

Conflict of interest:

None to declare

Authors Contributions:

DJH drafted the original paper. GNS, JC, MY, MT, DR, CC and JK were involved in drafting the manuscript and revising it critically. All authors have given approval of the final version to be published. 
Elite football of 2030 will not be the same as that of 2020: What has evolved and what needs to evolve?

Sport scientists must have an intimate understanding of the determinants of performance, the complexities of the adaptive response, the nature of the training stimulus and its assessment. ${ }^{1}$

— Prof. Tom Reilly

We read with interest the recent editorial by Nassis et $\mathrm{al}^{2}$ on future demands of elite football. Here we add to this evolving conversation by providing some practical considerations around the future physical preparation of elite players for high-intensity locomotor demands not explicitly addressed in the editorial. We also feel that women's football should feature in this discussion, given its rapidly growing profile and professionalism ${ }^{3}$, while evidence from the 2015 and 2019 women's World Cups illustrates that high-intensity running demands could be increasing at a greater rate than men's. ${ }^{3}$

Whilst we agree with Nassis et $\mathrm{al}^{2}$ that the future game will be played at higher speeds, it is important to note that the English Premier League study ${ }^{4}$ used by the authors ${ }^{2}$ to forecast increases in high-intensity running used absolute high-speed running and sprinting zones. Importantly, for the purposes of accurately informing the preparation of elite players, these arbitrary high-intensity running thresholds do not capture accelerations or decelerations, reflect the relative proportion of an individual's anaerobic speed reserve (ASR), nor consider individual player movement, tactical and technical demands that are important for position specific training ${ }^{5}$ and rehabilitation. ${ }^{6}$

We suggest that tactical evolutions of the future game, predicated on models of high-intensity pressing, counter pressing, and counterattacking, will result in greater exposure to intense, short accelerations and decelerations, interspersed between more high-speed running moments. ${ }^{6}$ Accordingly, the creation of high-intensity locomotor profiles may be especially insightful for individualizing load demands and accurately informing training prescriptions (Figure 1). Such a profile could include maximal: (1) acceleration, (2) deceleration (3) maximal aerobic speed (MAS) and (4) maximal sprinting speed (MSS) metrics — with the latter two components enabling evaluation of anaerobic speed reserve. Clearly, although beyond the scope of this letter, future players will also require concurrent improvements in high-speed decision-making skills.

< INSERT FIGURE 1 HERE > 
We see the locomotor profile having the biggest impact on physical preparation and performance through:

1. Raising the 'ceiling': Advanced field-based profiling will identify individual specific training needs enabling the 'ceiling' to be raised in each high-intensity locomotor skill through individualized training. Raising the 'ceiling' will improve player capacity to repeat and recover from dense high-intensity running loads.

2. Braking performance capabilities: The development and refinement of deceleration metrics, and the design of corresponding training interventions, will enhance braking performance capabilities, facilitating game-specific speed abilities and reduced predisposition to fatigue and injury.

3. Precision monitoring: Small embedded micro-technologies will provide advanced, in-situ, precise physiological and mechanical insights into high-intensity locomotor performances. Such data, when analysed using evolving machine learning algorithms, should provide information to more accurately inform coaching, sport science and medicine practitioner's decision-making processes.

4. Precision loading: New technologies will enable precise loading of specific forcevelocity components required for each high-intensity locomotor skill. For example, portable motorised electronic systems can be used to create assisted and resisted player specific acceleration, deceleration and MSS training prescriptions.

In summary, the future game will demand an increasing priority on 'individualization'. We offer the locomotor profile as a key tool that may help us navigate the complexity of future game demands. 


\section{References}

1. Reilly T, Morris T, Whyte G. The specificity of training prescription and physiological assessment: a review. J Sports Sci. 2009;27(6):575-589.

doi:10.1080/02640410902729741

2. Nassis GP, Massey A, Jacobsen P, et al. Elite football of 2030 will not be the same as that of 2020: Preparing players, coaches, and support staff for the evolution. Scand $J$ Med Sci Sports. 2020;30(6):962-964. doi:10.1111/sms.13681

3. Bradley P, Scott D. Physical analysis of the FIFA women's world cup France 2019. FIFA.com. https://img.fifa.com/image/upload/zijqly4oednqa5gffgaz.pdf. Published 2020. Accessed July 8, 2020.

4. Barnes C, Archer DT, Hogg B, Bush M, Bradley PS. The evolution of physical and technical performance parameters in the English Premier League. Int J Sports Med. 2014;35:1095-1100. doi:10.1055/s-0034-1375695

5. Ade J, Fitzpatrick J, Bradley PS. High-intensity efforts in elite soccer matches and associated movement patterns, technical skills and tactical actions. Information for position-specific training drills. J Sports Sci. 2016;34(24):2205-2214. doi:10.1080/02640414.2016.1217343

6. Taberner M, Allen T, Cohen DD. Progressing rehabilitation after injury: consider the “control-chaos continuum”. Br J Sports Med. 2019;53(18):1132-1136.

doi:10.1136/bjsports-2018-100157 


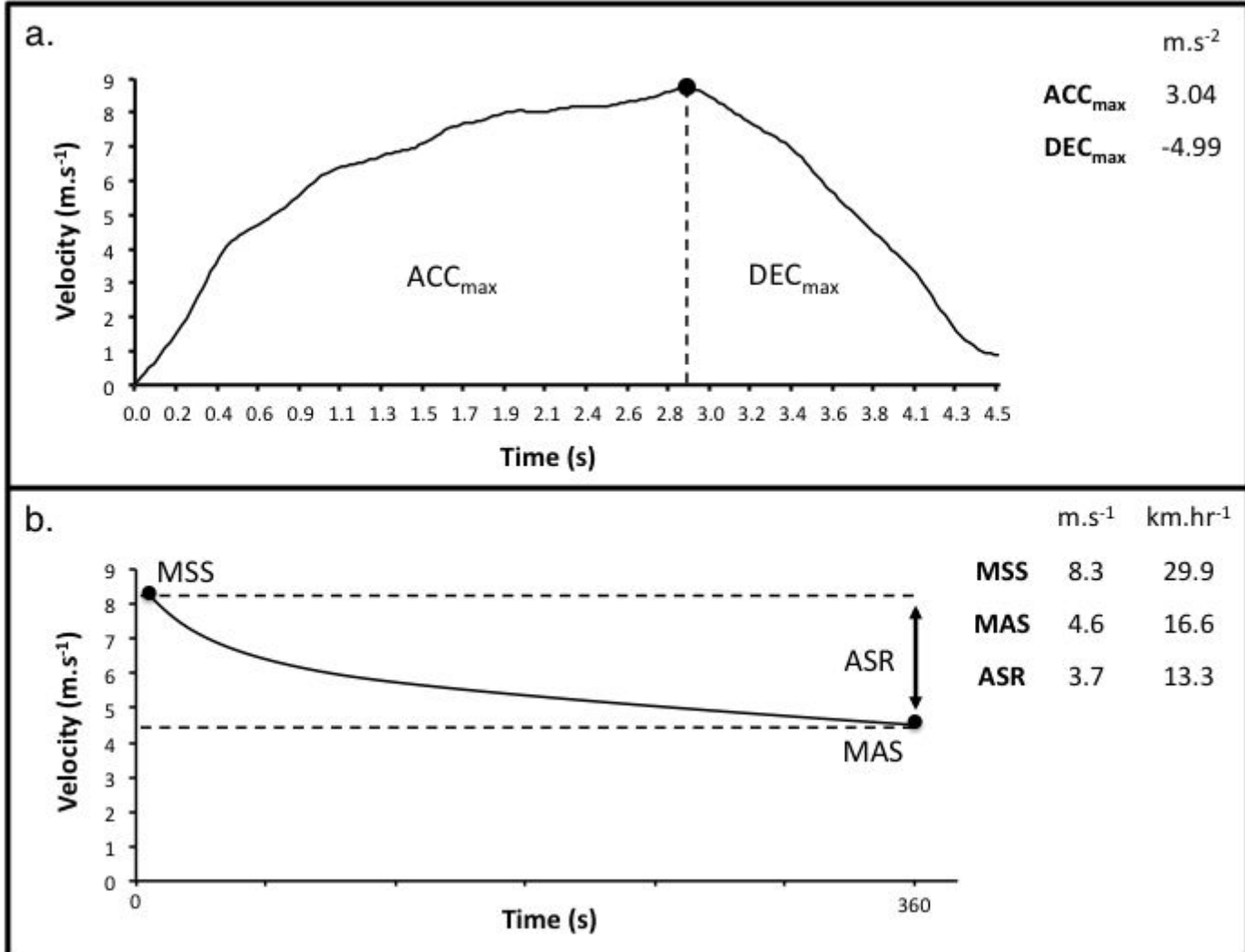

Figure 1. Example of individual player high-intensity locomotor profile (a) maximal acceleration $\left(\mathrm{ACC}_{\max }\right)$ and deceleration $\left(\mathrm{DEC}_{\max }\right.$ ) and (b) anaerobic speed reserve (ASR) calculated as the speed range between a players maximal sprinting speed (MSS) and maximal aerobic speed (MAS). 